\title{
Chemoenzymatic Epoxidation of Highly Unsaturated FAME and its Application as Poly(lactic acid) Plasticizer
}

\author{
Alejandro Sustaita-Rodríguez, Alejandro Vega-Rios, Alejandro Bugarin, Víctor $\mathbf{H}$. \\ Ramos-Sánchez, Alejandro A. Camacho-Dávila, Beatriz Rocha-Gutiérrez, and David \\ Chávez-Flores* \\ *Corresponding author e-mail address: dchavezf@uach.mx
}

Pages: 9

Figures: 8

Tables: 0 


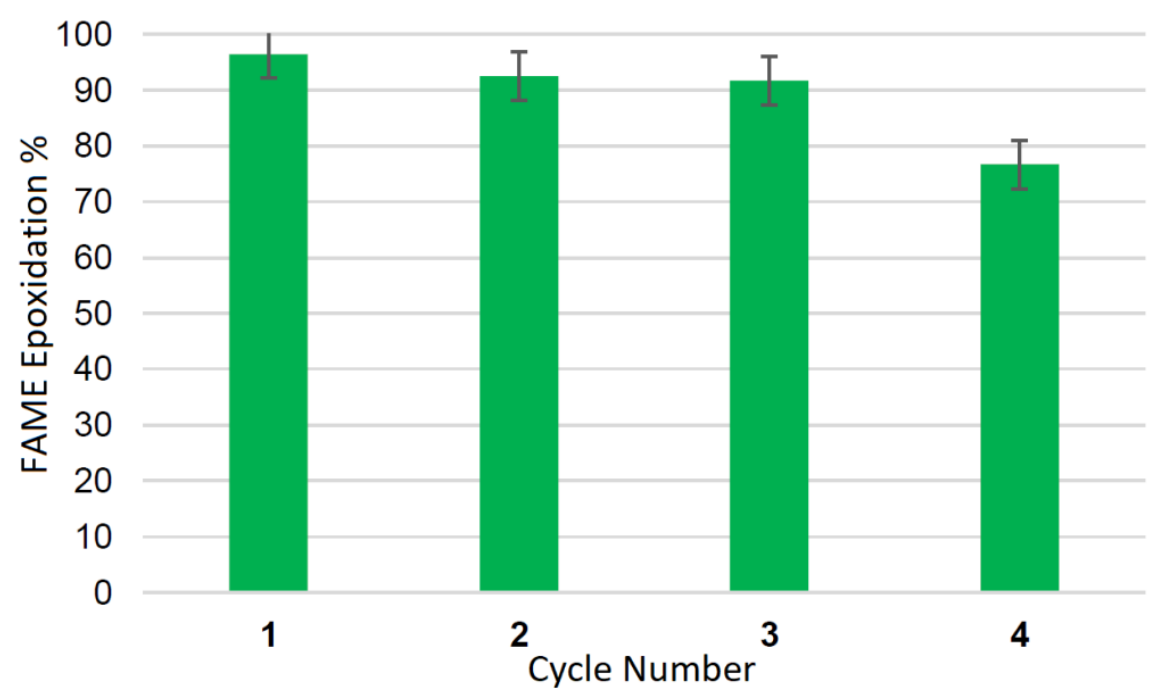

Figure S1. Reusability cycles of the Candida antarctica lipase for the FAME-GSO epoxidation reaction. 

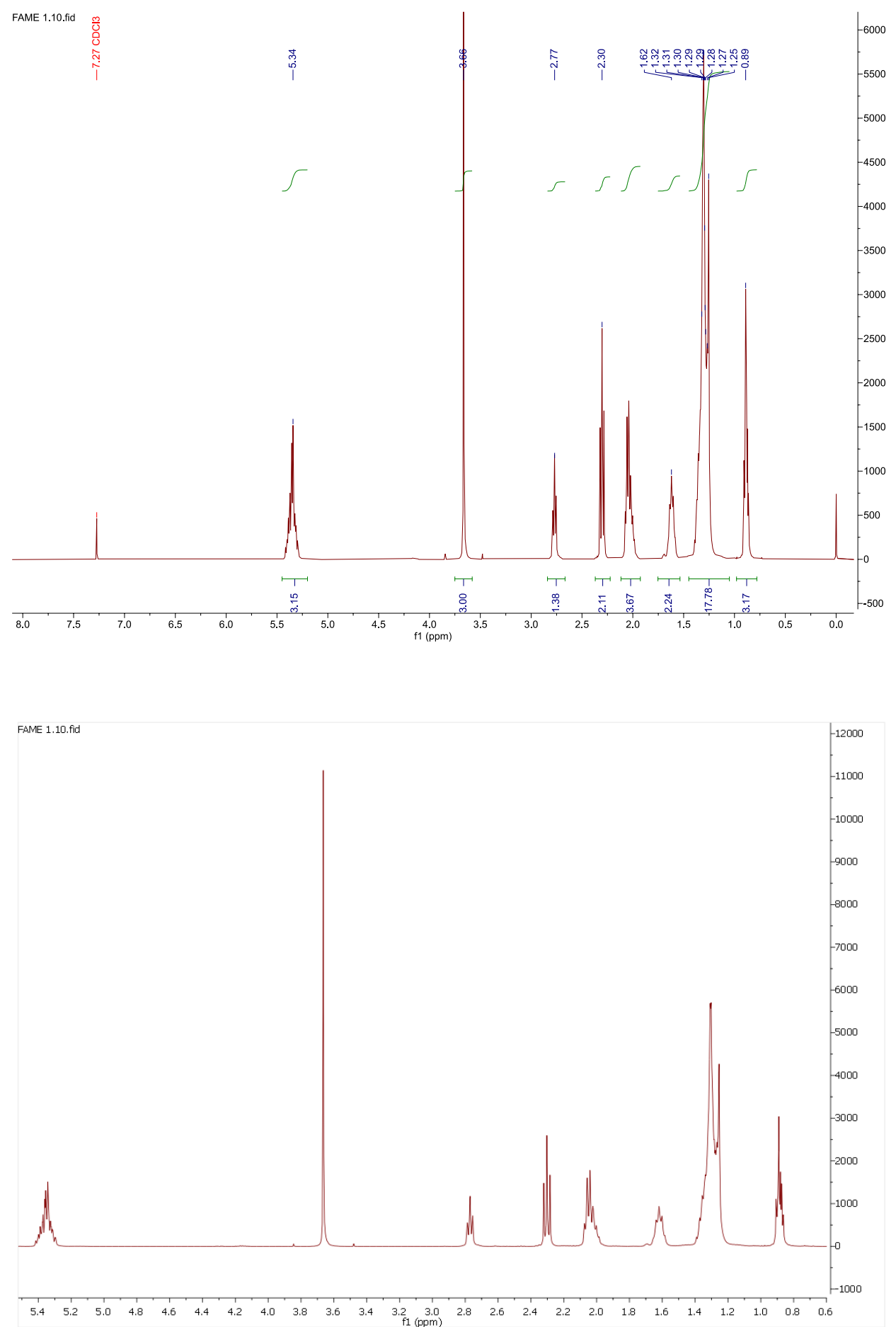

Figure S2. Integrated ${ }^{1} \mathrm{H}-\mathrm{NMR}$ spectrum of grape seed oil FAME in $\mathrm{CDCl}_{3}$ (top image), zoom from 0.6 to $5.5 \mathrm{ppm}$ (bottom image) 

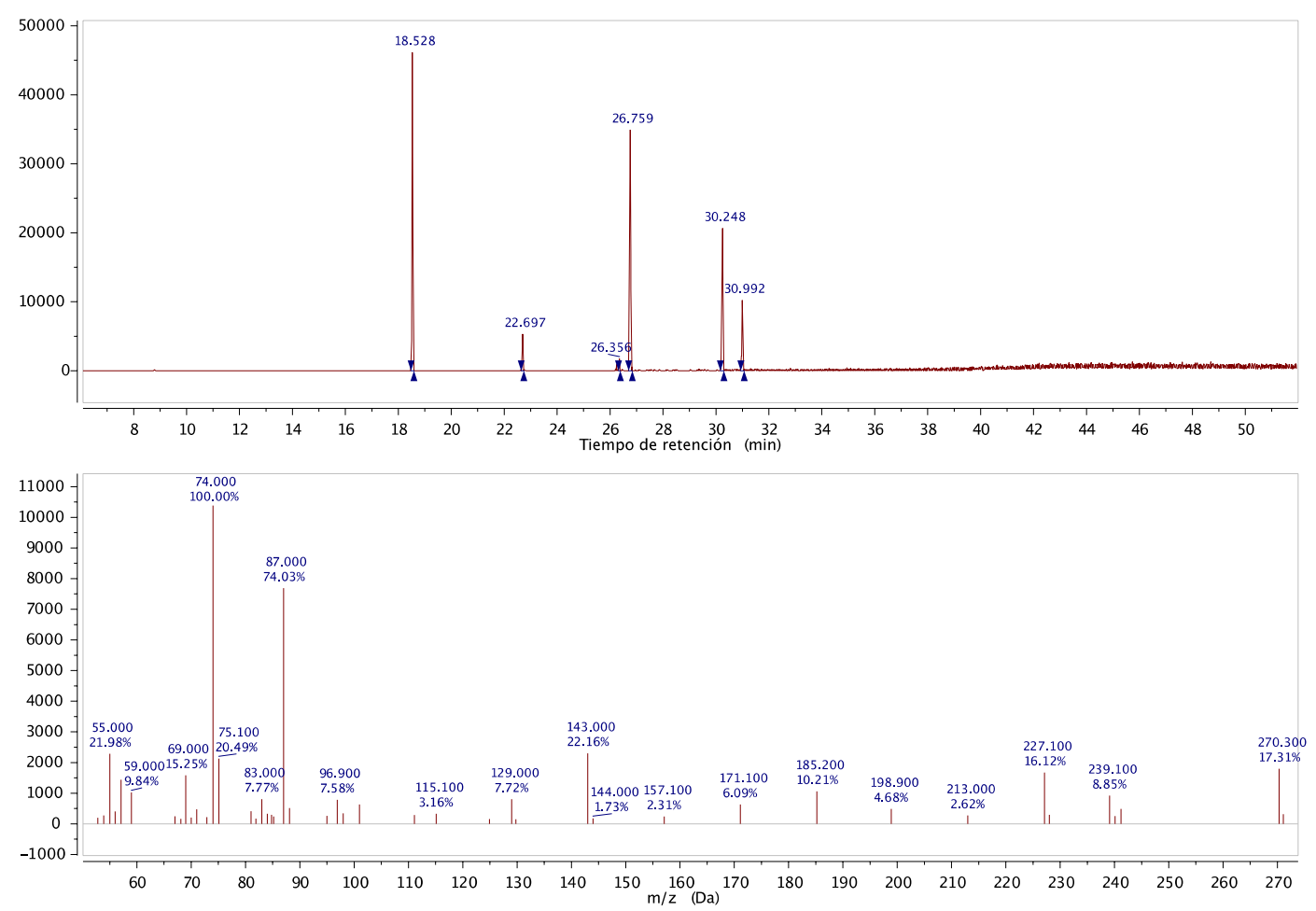

Figure S3. GC-Chromatogram of the FAME-GSO (top), Mass Spectum (bottom) 


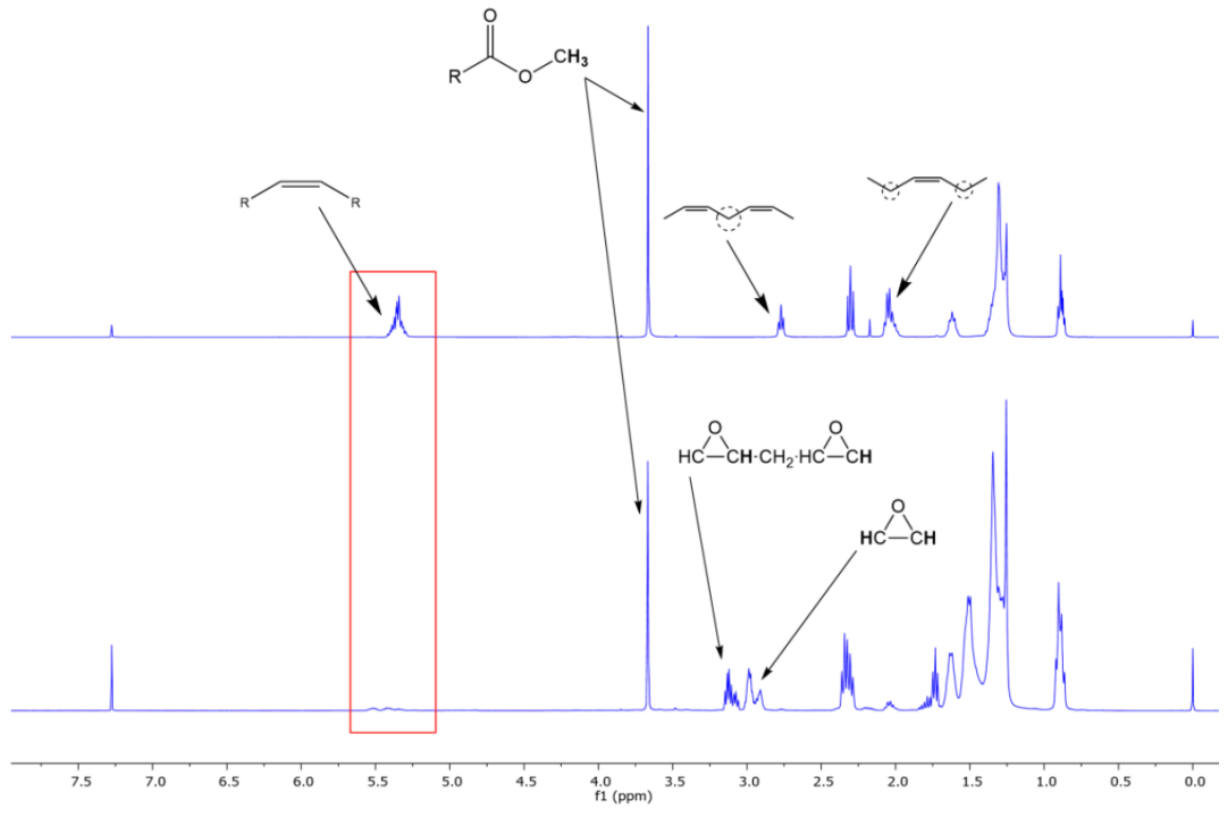

Figure S4. Comparison of FAME and EGSFO ${ }^{1} \mathrm{H}-\mathrm{NMR}$ spectrum in $\mathrm{CDCl}_{3}$.

St 

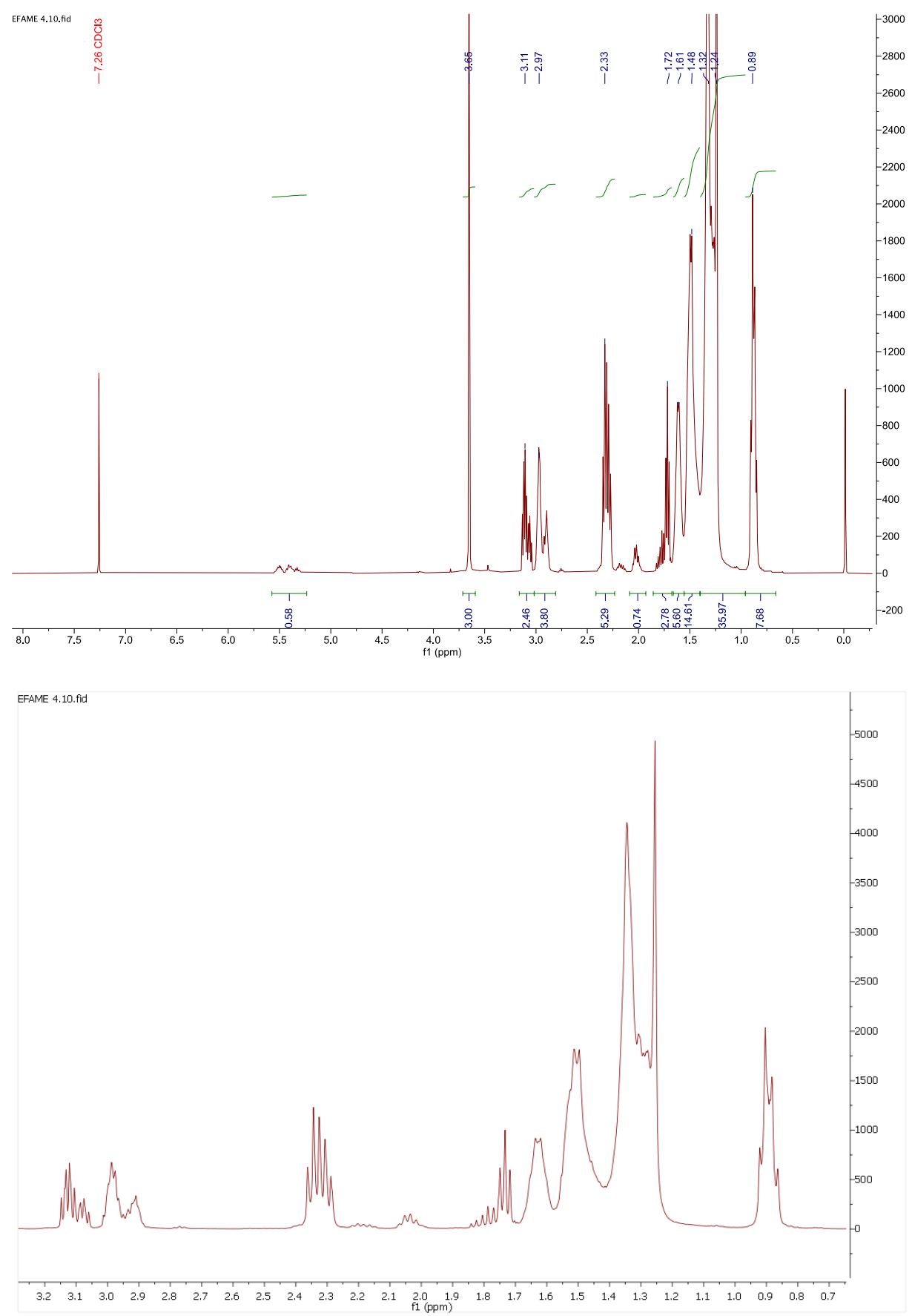

Figure S5. Integrated ${ }^{1} \mathrm{H}-\mathrm{NMR}$ spectrum of EGSFO in $\mathrm{CDCl}_{3}$ (top image), zoom from 0.6 to 3.3 ppm (bottom image) 

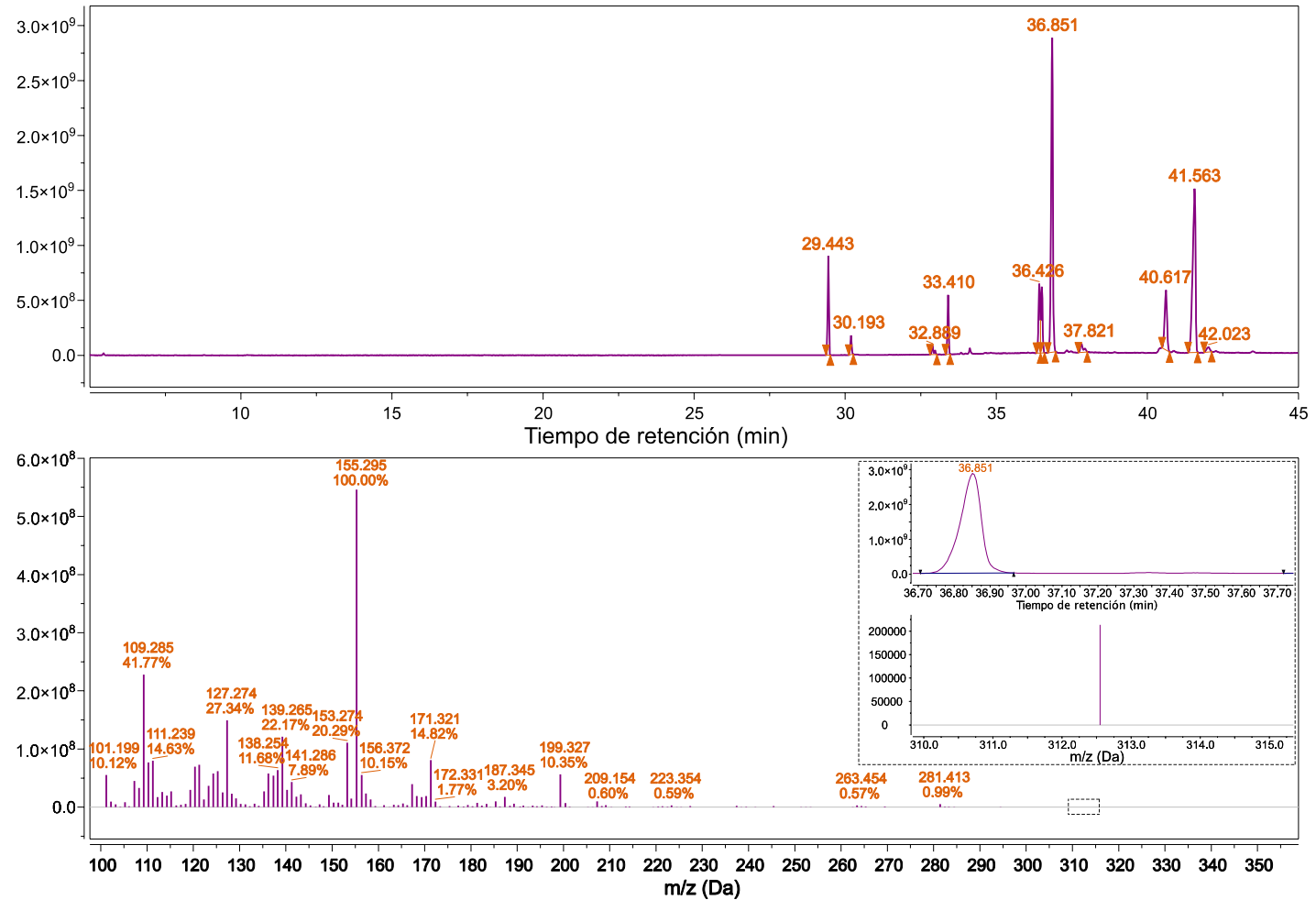

Figure S6. Chromatogram of the epoxidation reaction products (EGSFO). 

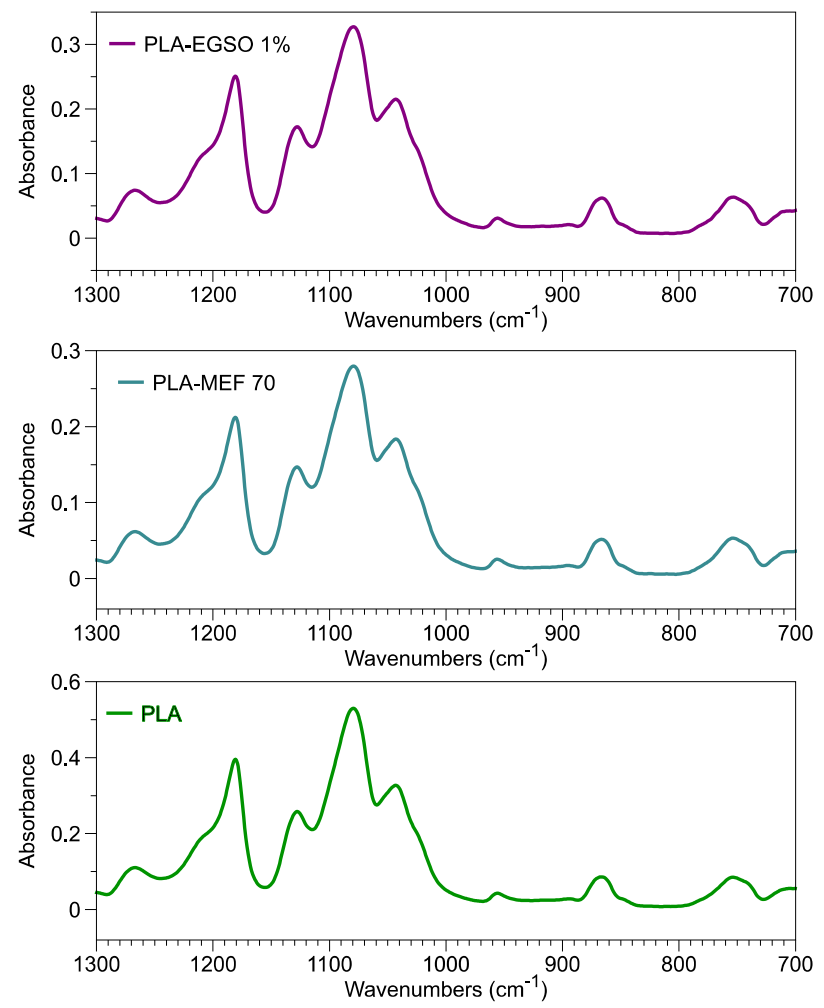

Figure S7. Comparison of infrared spectra. PLA-EGSFO 1\%, PLA-MEF 70, and PLA. 

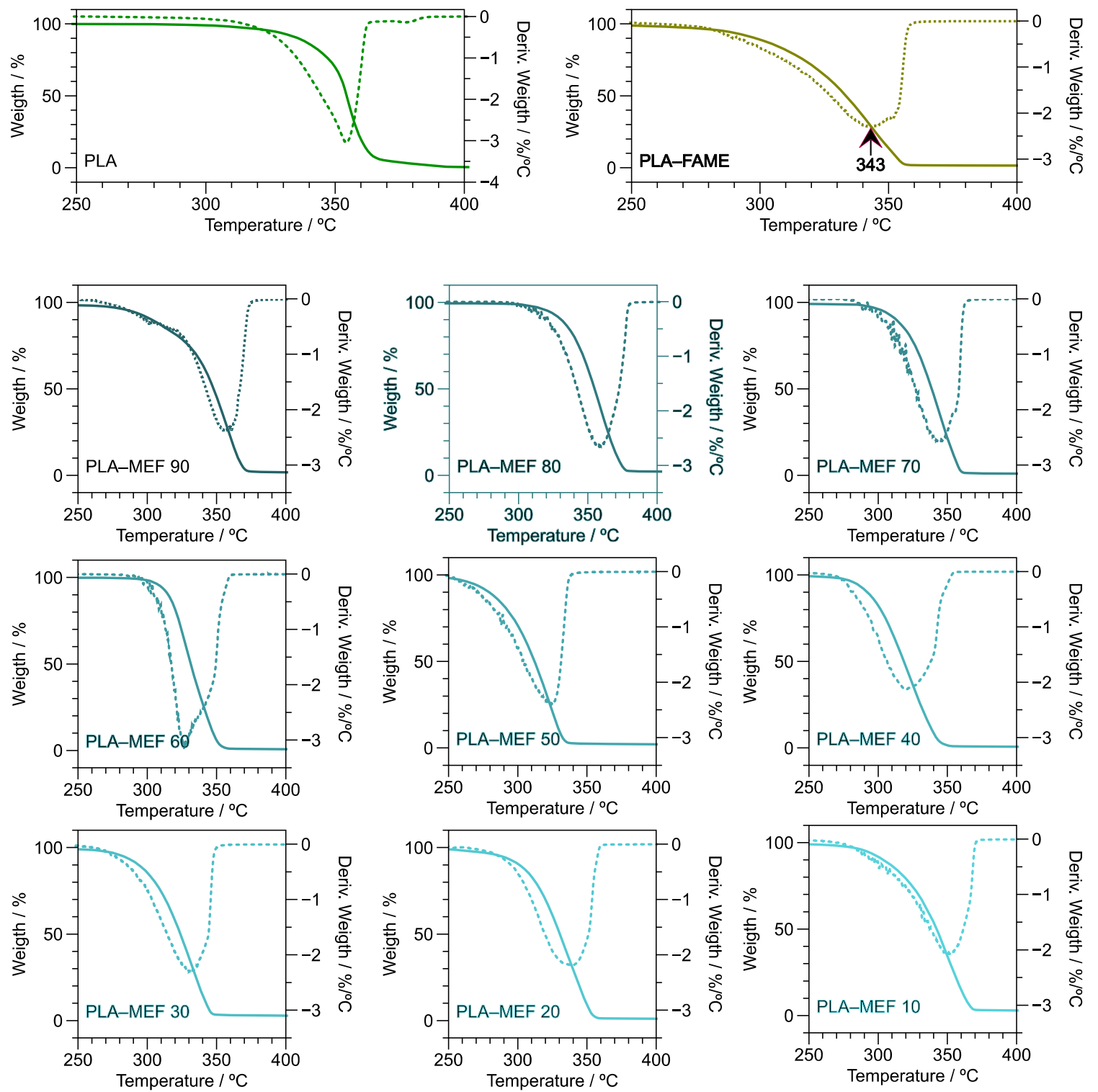

Figure S8. TGA/DTGA of the neat PLA, PLA/FAME-GSO, and PLA-MEF blends. 